\title{
Portal Vein Embolization for Hepatocellular Carcinoma
}

\author{
Junichi Shindoh Ching-Wei D. Tzeng Jean-Nicolas Vauthey \\ Department of Surgical Oncology, The University of Texas MD Anderson Cancer Center, USA
}

\section{Key Words}

Hepatocellular Carcinoma · Portal Vein Embolization · Transarterial Chemoembolization

\begin{abstract}
Portal vein embolization (PVE) improves the safety of major hepatectomy through hypertrophy of the future liver remnant (FLR), atrophy of the liver volume to be resected, and improvement in patient selection. Because most patients with hepatocellular carcinoma (HCC) have liver parenchymal injury due to underlying viral hepatitis or alcoholic liver fibrosis/cirrhosis, indication of PVE is relatively complex and sequential procedures, including transarterial chemoembolization, are required to maximize the effect of PVE as well as to minimize tumor progression due to increased arterial flow after PVE. PVE is currently indicated for patients with relatively well-preserved hepatic function [Child-Pugh A and indocyanine green tolerance test (ICG-R15) <20\%] to achieve minimal FLR volume for safe major hepatectomy. FLR volume $>40 \%$ is the minimal requirement for patients with chronic hepatitis or cirrhosis, and further strict criteria (FLR volume $>50 \%$ ) have been recommended for patients with marginal liver functional reserve (ICG-R15, 10-20\%). Recent clinical results have suggested that PVE can be safely performed in patients with HCC and that it contributes to improved survival after major hepatectomy.

Copyright $(2012$ S. Karger AG, Basel
\end{abstract}

\section{Introduction}

Although hepatic resection is the only curative treatment option for large hepatocellular carcinoma (HCC), it is often precluded by the presence of underlying chronic liver disease. Major hepatic resection in patients with liver fibrosis or cirrhosis can lead to an abrupt increase in portal venous pressure and insufficient hepatic functional reserve, both of which

Jean-Nicolas Vauthey, MD

Department of Surgical Oncology, The University of Texas MD Anderson Cancer Center

1515 Holcomb Boulevard, Unit 1484, Houston, TX 77030, (USA)

Tel. +1 713792 2022, E-mail jvauthey@mdanderson.org 
Fig. 1. Volume changes in FLR and embolized liver postPVE.

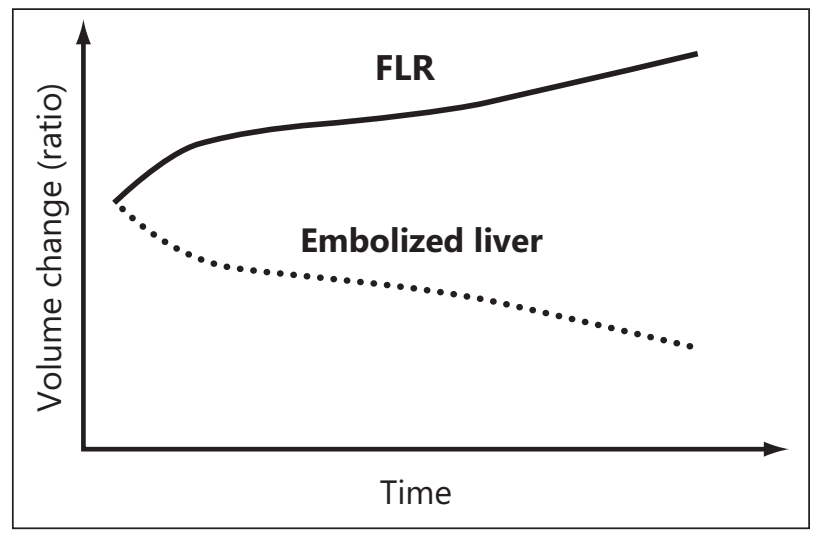

increase postoperative morbidity and mortality. To overcome these issues, portal vein embolization (PVE) has been increasingly used to induce volume growth of the future liver remnant (FLR) and atrophy of the liver to be resected. Since its original description for hilar cholangiocarcinoma, indications for PVE have expanded to include any primary or metastatic liver cancer requiring better FLR prior to attempted resection $[1,2]$. In this review, we highlight the indications, technical details, and clinical outcomes of PVE for patients with HCC.

\section{Atrophy-Hypertrophy Complex and Liver Regeneration}

The atrophy-hypertrophy complex refers to the liver's response to hepatocellular loss by controlled restoration of liver parenchyma [3]. Regardless of the cause of cellular loss in the liver, hypertrophy is relatively constant when there is a minimum amount of functional liver remnant. Occlusion of the portal vein induces hepatic ischemia, resulting in progressive anoxia especially in the pericentral regions of the liver lobule [4,5]. Atrophy in the embolized part of the liver occurs due to necrosis and/or apoptosis of hepatocytes through ischemia/ reperfusion injury. Volume increase in the nonembolized liver is simultaneously induced by increased endothelial shear stress, hepatocellular swelling, and activated growth factors/ cytokines due to increased portal flow [3].

Volume growth in FLR and atrophy of the embolized liver usually occur as a mirror image (fig. 1), and these reportedly continue for at least one year after PVE [6]. Generally, the regeneration curve shows a nonlinear pattern characterized by (i) initial rapid growth within 3-4 weeks postPVE, (ii) a plateau period 5-8 weeks postPVE with minimal changes in FLR, and (iii) steady regrowth thereafter [6, 7]. Therefore, in some cases with unsatisfactory FLR regeneration, waiting beyond 8 weeks might yield the targeted FLR volume. While waiting for further FLR growth, local disease progression can be controlled by transarterial chemoembolization (TACE).

\section{Rationale and Indications for PVE}

Because the underlying liver is frequently impaired due to chronic hepatitis $\mathrm{B}$, hepatitis $\mathrm{C}$, or alcoholic fibrosis in patients with HCC, indications for PVE for HCC are relatively complex. PVE should be considered from the viewpoint of hepatic function, minimum volume requirement, and vascular anatomy (fig. 2). 
Fig. 2. Indications of PVE for patients with HCC.

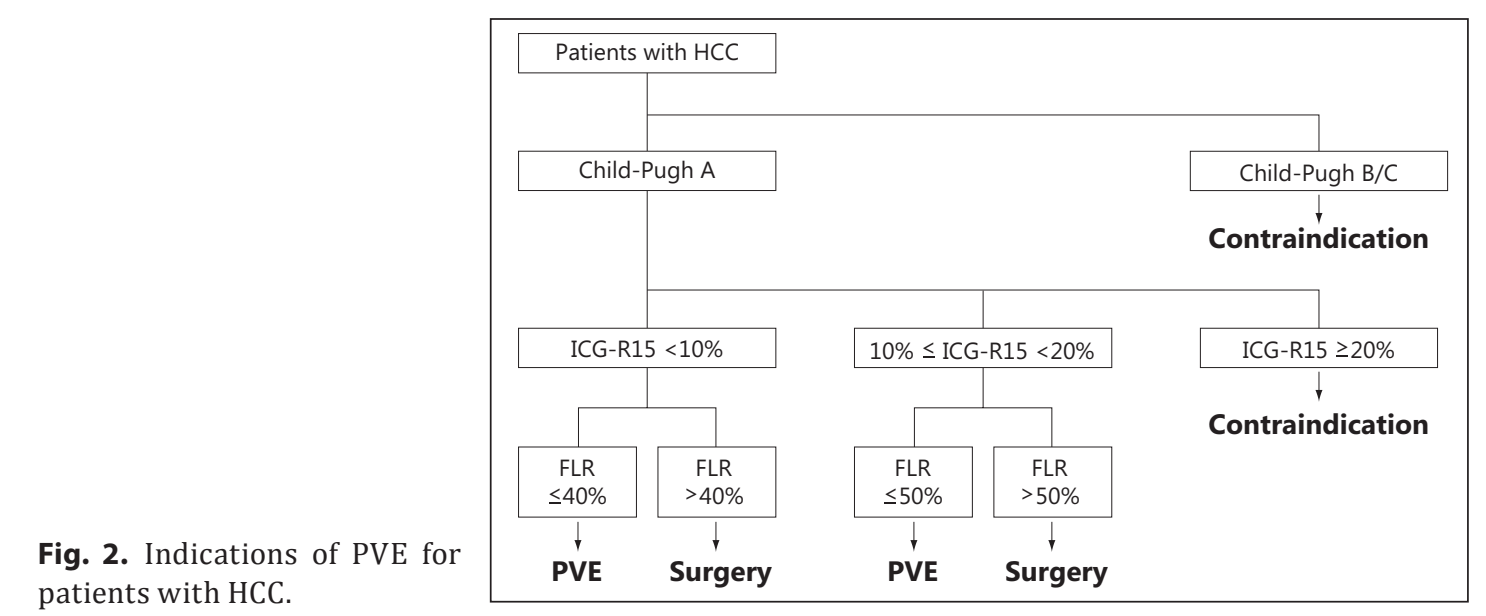

\section{Functional criteria}

Major hepatectomy is not indicated for patients classified as Child-Pugh B or C. In addition, patients with signs of established portal hypertension (i.e., thrombocytopenia, splenomegaly, esophageal varices, or portosystemic shunt) are also not suitable for PVE. Furthermore, even among patients classified as Child-Pugh A, those with indocyanine green tolerance test (ICG-R15) $>20 \%$ are not candidates for major hepatectomy postPVE.

\section{FLR criteria}

Inadequate FLR is a well-known cause of postoperative hepatic insufficiency and postoperative death from liver failure. One study investigating variation in FLR volume reported that $10 \%$ of patients undergoing right hemihepatectomy and $75 \%$ of those undergoing right trisectionectomy had FLR volume $\leq 20 \%$ [8]. To date, FLR volume $>40 \%$ has been recommended in patients with chronic hepatitis or cirrhosis [9-11], and our previous study confirmed a substantial postPVE risk reduction in patients with prePVE FLR volume $\leq 40 \%$ [12]. However, for patients with marginal hepatic functional reserve with ICG-R15 of 10-20\%, FLR >50\% has been recommended by several authors $[9,13]$.

Beyond the size criteria, adequate FLR must have regenerative capacity. Ribero et al. reported that the degree of hypertrophy (DH) in FLR volume postPVE may independently predict the surgical outcome [7]. PostPVE DH $>5 \%$ plus FLR $>20 \%$ predicted good postoperative outcomes with high specificity and sensitivity in patients with normal liver function. However, the cutoff value for DH in patients with chronic liver disease remains unclear. Our preliminary results in a small cohort of patients with HCC $(n=32)$ have shown that DH $>10 \%$ is the best cutoff value to prevent postoperative hepatic insufficiency (unpublished data).

\section{Anatomic criteria}

With recent advancements in embolization techniques, PVE can be performed relatively safely with minimal risk of complications [7]. However, this procedure is contraindicated in patients with tumor thrombi extending to the portal pedicle for FLR or in those with a rare vascular anomaly, including lack of portal bifurcation [14] or lack of intrahepatic portal vein (Abernethy anomaly [15]). Therefore, precise anatomic assessments and technical planning (i.e., approach and portal branches to be embolized) using enhanced computed tomography (CT) and/or ultrasonography are unavoidable before PVE. 


\section{Technique and Approach to Optimizing FLR Regeneration}

\section{Volumetry and calculation of standardized FLR}

CT volumetry estimation of FLR pre- and post PVE is essential for selecting patients for PVE and to assess its effects. Volume measurement is usually performed using either the conventional hand-trace method [9] or the recently developed three-dimensional liver simulators $[16,17]$, according to local expertise. The FLR volume is then standardized using the ratio to total liver volume [9] or standard liver volume, which is calculated by relevant formulas [18].

\section{Basic approach and embolization technique}

There are three main approaches for PVE-transileocolic PVE, ipsilateral percutaneous transhepatic PVE (ipsilateral PTPE), and contralateral PTPE. Advantages and disadvantages of these three approaches are summarized in table 1.

In general, ipsilateral PTPE is the most technically demanding approach but is currently the most preferred because of its low invasiveness and easier access to segment 4 portal vein branches. The ipsilateral PTPE approach was first described by Nagino et al. [19] in the mid-1990s, and it is now utilized worldwide [20-22]. Portal venous access is obtained via the tumor-bearing side of the liver rather than FLR. One major advantage is that possible injury to FLR or risk of portal vein thrombosis on the FLR side can be minimized. In addition, if embolization of segment 4 portal pedicles is required, more straightforward access to the segment 4 portal veins can be obtained. At our institution between 1995 and 2011, 228 patients underwent embolization of the right portal vein + segment 4 portal veins using the ipsilateral percutaneous approach for potentially resectable tumors. Among these, PVE was completed in 226 (99.2\%), and postprocedure complication was observed in 11 (4.8\%) patients. Major complications requiring surgical management were observed in only two $(0.9 \%)$ patients with portal vein thrombosis secondary to PVE.

\section{Additional methods to optimize FLR regeneration rate}

1. Segment 4 embolization

The additional effect of embolization of segment 4 on right PVE was first reported by Nagino et al. investigating the hypertrophy ratio of the left lateral section (segments $2+3$ ) postPVE. In their report, right PVE extending to segment 4 branches achieved a $50 \%$ increase in the FLR volume compared to that with right PVE alone, which achieved a 31\% increase $(\mathrm{P}<0.0005)$ [23]. A later study from our institution confirmed similar results with an increased FLR volume of $54 \%$ vs. $26 \%(P=0.02)$ [24].

2. Small spherical particles for embolization

Various embolic materials have been used for PVE. However, recent studies have confirmed that there is a difference in the embolic effects of different embolic materials. Madoff et al. demonstrated that embolization with small spherical particles provided improved hypertrophy (69\%) and resection rates compared with that with larger, nonspherical particles in patients undergoing right PVE + segment 4 embolization (46\% increase, $\mathrm{P}=0.001$ ) [21].

\section{Sequential TACE and PVE}

In patients with cirrhosis, liver regeneration may be impaired, causing concerns about tumor progression during the postPVE treatment break. To decrease the time without therapy, sequential use of TACE and PVE has been utilized for HCC. First, selective TACE is performed for the segments containing the HCC tumor (s). In the case of large HCCs, the tumor is often fed by other arterial branches such as a branch of segment 4 or the right inferior phrenic artery. These arterial branches need to be embolized in addition to maximization of 
Table 1. Comparison of portal venous access for right PVE

\begin{tabular}{|c|c|c|c|}
\hline & $\begin{array}{l}\text { Ipsilatelal } \\
\text { PTPE }\end{array}$ & $\begin{array}{l}\text { Contralateral } \\
\text { PTPE }\end{array}$ & TIPE \\
\hline Anesthesia & Local or General & Local or General & General \\
\hline Invasiveness & Low & Low & Moderate \\
\hline Injury to future liver remnant & - & + & - \\
\hline Access to right portal branches & Difficult & Easy & Easy \\
\hline Access to segment 4 branches & Easy & Difficult & Easy \\
\hline Completion portography & Impossible & Possible & Possible \\
\hline Risk of peritoneal seeding & + & + & - \\
\hline $\begin{array}{l}\text { Risk of subcapsular hematoma/ } \\
\text { hemorrhage }\end{array}$ & + & + & - \\
\hline Risk of biliary peritonitis & + & + & - \\
\hline Risk of ileus & - & - & + \\
\hline
\end{tabular}

TIPE = transileocolic portal embolization.

chemoembolization delivery to the tumor. Although interinstitutional interval between TACE and PVE varies, PVE can be performed as early as 7-10 days after TACE [25]. A recent study showed that sequential TACE and PVE is superior to PVE with regard to the FLR regeneration rate and in disease-free survival (DFS) after surgery [26].

\section{Hepatic vein embolization}

In a small pilot study of 12 patients, Hwang et al. [27] reported that hepatic vein embolization following PVE may accelerate FLR regeneration. With limited clinical evidence, hepatic vein embolization remains investigational in its use as an adjunct after PVE for patients with insufficient FLR growth.

5. Associating liver partition and portal vein ligation for staged hepatectomy (ALPPS) approach to achieve rapid FLR hypertrophy

European groups have recently reported a novel approach to rapid liver regeneration in patients undergoing extended right hepatectomy, termed "ALPPS " [28] Surgeons perform right portal ligation and in situ splitting of the liver parenchyma on the right side of the umbilical portion of the portal vein. After median hospitalization of 9 days, patients were readmitted to the operating room for step 2 of the staged operation for extended hepatectomy. The first case series reported a median volume increase rate of $74 \%$ after step 1 of this single-hospitalization staged procedure. Indeed, this approach may be an option for patients with very small FLR. However, reported major morbidity and mortality rates were as high as 40 and $12 \%$, respectively, with the latter being more than five times the national mortality rate for hepatectomy in the US [29]. Further investigation is needed before considering this procedure for HCC with underlying chronic liver disease, which may not regenerate in the 9-day time frame. 


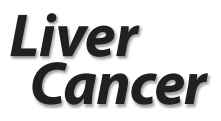

Table 2. Clinical postPVE outcomes for HCC

\begin{tabular}{|c|c|c|c|c|c|c|c|}
\hline Authors & Year & Design & $\mathrm{n}$ & $\begin{array}{c}\text { Morbidity } \\
(\%)\end{array}$ & $\begin{array}{c}\text { Mortality } \\
(\%)\end{array}$ & $\begin{array}{c}\text { 5-year } \\
\text { DFS (\%) }\end{array}$ & $\begin{array}{l}5 \text {-year } \\
\text { OS (\%) }\end{array}$ \\
\hline \multicolumn{8}{|l|}{ PVE } \\
\hline \multirow[t]{2}{*}{ Azoulay et al. [31] } & 2000 & Retrospective & 10 (PVE) & 55 & 0 & 21 & 44 \\
\hline & & & 19 (Control) & 57 & 0 & 17 & 53 \\
\hline \multirow[t]{2}{*}{ Tanaka et al. [32] } & 2000 & Retrospective & 33 (PVE) & - & 3 & 33 & 50 \\
\hline & & & 38 (Control) & - & 5 & 20 & 25 \\
\hline \multirow[t]{2}{*}{ Wakabayashi et al. [33] } & 2001 & Retrospective & 26 (PVE) & - & 11.5 & 40 & 46 \\
\hline & & & 43 (Control) & - & 3.5 & 46 & 53 \\
\hline \multirow[t]{2}{*}{ Palavecino et al. [12] } & 2009 & Retrospective & 21 (PVE) & 24 & 0 & 56 & 72 \\
\hline & & & 33 (Control) & 36 & 18 & 49 & 54 \\
\hline Seo et al. [30] & 2007 & Retrospective & 32 (PVE) & 19 & 0 & 37 & 72 \\
\hline \multicolumn{8}{|l|}{ TACE+PVE } \\
\hline \multirow[t]{2}{*}{ Ogata et al. [26] } & 2006 & Retrospective & 18 (TACE+PVE) & 39 & - & 37 & - \\
\hline & & & 18 (PVE) & 56 & - & 19 & - \\
\hline Aoki et al. [25] & 2004 & Retrospective & 24 (TACE+PVE) & 24 & 0 & 47 & 56 \\
\hline
\end{tabular}

\section{Clinical Outcomes}

\section{Long-term outcome}

In contrast to biliary cancer or colorectal liver metastases, the number of reports on the long-term outcomes for HCC is relatively limited (table 2). However, reported outcomes suggest that major resection for HCC postPVE may yield satisfactory long-term outcome that is comparable to or even superior to major resection without PVE [12, 25, 26, 30-33]. This would imply that patients who would otherwise have unresectable tumors without PVE may have similar postoperative oncologic outcomes to patients with resectable tumors who did not need PVE.

\section{Tumor growth after PVE and rationale for TACE + PVE}

Because HCC is a hypervascular tumor, hemodynamic modulation by PVE may cause compensatory increase in the arterial flow to the tumor, which could trigger an increase in the tumor size. Although clinical data on tumor growth after PVE are scarce, Hayashi et al. reported that HCC tumor growth was accelerated 2.65-fold after PVE in six patients, while the acceleration rate was only 1.16 -fold in two patients with intrahepatic cholangiocarcinoma [34]. They concluded that hemodynamic modulation after PVE may facilitate HCC tumor progression. 
Aoki et al. reported that resected specimens demonstrated $>70 \%$ necrosis in $75 \%$ of patients undergoing sequential TACE and PVE and that tumor markers (alpha-fetoprotein and des-gamma carboxyprothrombin) were significantly suppressed after these procedures [25]. Similarly, Ogata et al. reported high complete tumor necrosis rates (83\%) and better diseasefree survival in patients treated with sequential TACE and PVE [26]. Although validation with a larger cohort is needed, these clinical results suggest that sequential TACE and PVE may have oncologic advantages beyond their accelerative effects in volume regeneration.

\section{Conclusions}

PVE can be safely performed in patients with HCC and can increase the number of candidates for major and extended hepatectomy. By testing the degree of hypertrophy of FLR, PVE can help decrease posthepatectomy mortality through more careful patient selection. By stimulating hypertrophy of FLR to an adequate volume, PVE can decrease postoperative hepatic insufficiency and posthepatectomy mortality. Although there is concern regarding HCC progression associated with postPVE hemodynamic changes [34], prePVE TACE may offer improved pathologic tumor response and possibly better surgical outcomes. Optimization of the PVE technique to include small spherical embolization particles [21], segment 4 embolization $[23,24]$, and sequential TACE and PVE $[25,26]$ has improved the FLR regeneration rate. With extended use of PVE for HCC in the future, more patients with inadequate FLR may become candidates for safe resection and enjoy longer survival postresection.

\section{Acknowledgement}

The University of Texas MD Anderson Cancer Center is supported in part by the National Institutes of Health through Cancer Center Support Grant CA016672.

\section{Conflicts of Interest}

None.

\section{References}

1 Makuuchi M: Preoperative transcatheter embolization of the portal venous branch for patients receiving extended lobectomy dur to the bile duct carcinoma. J Jpn Surg Assoc 1982;45:1558-1564.

2 Makuuchi M, Thai BL, Takayasu K, Takayama T, Kosuge T, Gunven P, Yamazaki S, Hasegawa H, Ozaki H: Preoperative portal embolization to increase safety of major hepatectomy for hilar bile duct carcinoma: a preliminary report. Surgery 1990;107:521-527.

3 Kim RD, Kim JS, Watanabe G, Mohuczy D, Behrns KE: Liver regeneration and the atrophy-hypertrophy complex. Semin Intervent Radiol 2008;25:92-103.

4 Jungermann K, Kietzmann T: Oxygen: modulator of metabolic zonation and disease of the liver. Hepatology 2000;31:255-260.

5 Lemasters JJ, Ji S, Thurman RG: Centrilobular injury following hypoxia in isolated, perfused rat liver. Science 1981;213:661-663.

6 Corrêa D, Schwartz L, Jarnagin WR, Tuorto S, DeMatteo R, D’Angelica M, Allen P, Brown K, Fong Y: Kinetics of liver volume changes in the first year after portal vein embolization. Arch Surg 2010;145:351-354, discussion 354-355.

7 Ribero D, Abdalla EK, Madoff DC, Donadon M, Loyer EM, Vauthey JN: Portal vein embolization before major hepatectomy and its effects on regeneration, resectability and outcome. Br J Surg 2007;94:1386-1394. 
8 Abdalla EK, Denys A, Chevalier P, Nemr RA, Vauthey JN: Total and segmental liver volume variations: implications for liver surgery. Surgery 2004;135:404-410.

9 Kubota K, Makuuchi M, Kusaka K, Kobayashi T, Miki K, Hasegawa K, Harihara Y, Takayama T: Measurement of liver volume and hepatic functional reserve as a guide to decision-making in resectional surgery for hepatic tumors. Hepatology 1997;26:1176-1181.

10 Shirabe K, Shimada M, Gion T, Hasegawa H, Takenaka K, Utsunomiya T, Sugimachi K: Postoperative liver failure after major hepatic resection for hepatocellular carcinoma in the modern era with special reference to remnant liver volume. J Am Coll Surg 1999;188:304-309.

11 Zorzi D, Laurent A, Pawlik TM, Lauwers GY, Vauthey JN, Abdalla EK: Chemotherapy-associated hepatotoxicity and surgery for colorectal liver metastases. Br J Surg 2007;94:274-286.

12 Palavecino M, Chun YS, Madoff DC, Zorzi D, Kishi Y, Kaseb AO, Curley SA, Abdalla EK, Vauthey JN: Major hepatic resection for hepatocellular carcinoma with or without portal vein embolization: Perioperative outcome and survival. Surgery 2009;145:399-405.

13 Makuuchi M, Kosuge T, Takayama T, Yamazaki S, Kakazu T, Miyagawa S, Kawasaki S: Surgery for small liver cancers. Semin Surg Oncol 1993;9:298-304.

14 Couinaud C: Le foie: études anatomiques et chirugicales. In: Paris: Masson, 1954.

15 Abernethy J: Account of two instances of uncommon formation, in the viscera of the human body. Philos Trans R Soc Lond B Biol Sci 1793;83:59-66.

16 Mise Y, Hasegawa K, Satou S, Aoki T, Beck Y, Sugawara Y, Makuuchi M, Kokudo N: Venous reconstruction based on virtual liver resection to avoid congestion in the liver remnant. Br J Surg 2011;98:1742-1751.

17 Shindoh J, Mise Y, Satou S, Sugawara Y, Kokudo N: The intersegmental plane of the liver is not always flattricks for anatomical liver resection. Ann Surg 2010;251:917-922.

18 Vauthey JN, Abdalla EK, Doherty DA, Gertsch P, Fenstermacher MJ, Loyer EM, Lerut J, Materne R, Wang X, Encarnacion A, Herron D, Mathey C, Ferrari G, Charnsangavej C, Do KA, Denys A: Body surface area and body weight predict total liver volume in Western adults. Liver Transpl 2002;8:233-240.

19 Nagino M, Nimura Y, Kamiya J, Kondo S, Kanai M: Selective percutaneous transhepatic embolization of the portal vein in preparation for extensive liver resection: the ipsilateral approach. Radiology 1996;200:559-563.

20 Gibo M, Unten S, Yogi A, Nakayama T, Ayukawa Y, Gibo S, Murayama S, Takara M, Shiraishi M: Percutaneous ipsilateral portal vein embolization using a modified four-lumen balloon catheter with fibrin glue: initial clinical experience. Radiat Med 2007;25:164-172.

21 Madoff DC, Abdalla EK, Gupta S, Wu TT, Morris JS, Denys A, Wallace MJ, Morello FA Jr, Ahrar K, Murthy R, Lunagomez S, Hicks ME, Vauthey JN: Transhepatic ipsilateral right portal vein embolization extended to segment IV: improving hypertrophy and resection outcomes with spherical particles and coils. J Vasc Interv Radiol 2005;16:215-225.

22 Madoff DC, Hicks ME, Abdalla EK, Morris JS, Vauthey JN: Portal vein embolization with polyvinyl alcohol particles and coils in preparation for major liver resection for hepatobiliary malignancy: safety and effectiveness-study in 26 patients. Radiology 2003;227:251-260.

23 Nagino M, Kamiya J, Kanai M, Uesaka K, Sano T, Yamamoto H, Hayakawa N, Nimura Y: Right trisegment portal vein embolization for biliary tract carcinoma: technique and clinical utility. Surgery 2000;127:155160.

24 Kishi Y, Madoff DC, Abdalla EK, Palavecino M, Ribero D, Chun YS, Vauthey JN: Is embolization of segment 4 portal veins before extended right hepatectomy justified? Surgery 2008;144:744-751.

25 Aoki T, Imamura H, Hasegawa K, Matsukura A, Sano K, Sugawara Y, Kokudo N, Makuuchi M: Sequential preoperative arterial and portal venous embolizations in patients with hepatocellular carcinoma. Arch Surg 2004;139:766-774.

26 Ogata S, Belghiti J, Farges O, Varma D, Sibert A, Vilgrain V: Sequential arterial and portal vein embolizations before right hepatectomy in patients with cirrhosis and hepatocellular carcinoma. Br J Surg 2006;93:1091-1098.

27 Hwang S, Lee SG, Ko GY, Kim BS, Sung KB, Kim MH, Lee SK, Hong HN: Sequential preoperative ipsilateral hepatic vein embolization after portal vein embolization to induce further liver regeneration in patients with hepatobiliary malignancy. Ann Surg 2009;249:608-616.

28 Schnitzbauer AA, Lang SA, Goessmann H, Nadalin S, Baumgart J, Farkas SA, Fichtner-Feigl S, Lorf T, Goralcyk A, Horbelt R, Kroemer A, Loss M, Rummele P, Scherer MN, Padberg W, Konigsrainer A, Lang H, Obed A, Schlitt HJ: Right portal vein ligation combined with in situ splitting induces rapid left lateral liver lobe hypertrophy enabling 2-staged extended right hepatic resection in small-for-size settings. Ann Surg 2012;255:405-414.

29 Aloia TA, Fahy BN, Fischer CP, Jones SL, Duchini A, Galati J, Gaber AO, Ghobrial RM, Bass BL: Predicting poor outcome following hepatectomy: analysis of 2313 hepatectomies in the NSQIP database. HPB (Oxford) 2009;11:510-515.

30 Seo DD, Lee HC, Jang MK, Min HJ, Kim KM, Lim YS, Chung YH, Lee YS, Suh DJ, Ko GY, Lee YJ, Lee SG: Preoperative portal vein embolization and surgical resection in patients with hepatocellular carcinoma and small future liver remnant volume: comparison with transarterial chemoembolization. Ann Surg Oncol 2007;14:3501-3509.

31 Azoulay D, Castaing D, Krissat J, Smail A, Hargreaves GM, Lemoine A, Emile JF, Bismuth H: Percutaneous portal vein embolization increases the feasibility and safety of major liver resection for hepatocellular carcinoma in injured liver. Ann Surg 2000;232:665-672. 
32 Tanaka H, Hirohashi K, Kubo S, Shuto T, Higaki I, Kinoshita H: Preoperative portal vein embolization improves prognosis after right hepatectomy for hepatocellular carcinoma in patients with impaired hepatic function. Br J Surg 2000;87:879-882.

33 Wakabayashi H, Ishimura K, Okano K, Izuishi K, Karasawa Y, Goda F, Maeba T, Maeta H: Is preoperative portal vein embolization effective in improving prognosis after major hepatic resection in patients with advanced-stage hepatocellular carcinoma? Cancer 2001;92:2384-2390.

34 Hayashi S, Baba Y, Ueno K, Nakajo M, Kubo F, Ueno S, Aikou T, Komokata T, Nakamura N, Sakata R: Acceleration of primary liver tumor growth rate in embolized hepatic lobe after portal vein embolization. Acta Radiol 2007;48:721-727. 